\title{
Optimal management of ADHD in older adults
}

This article was published in the following Dove Press journal:

Neuropsychiatric Disease and Treatment

8 January 2016

Number of times this article has been viewed

\author{
Terje Torgersen ${ }^{1,2}$ \\ Bjorn Gjervan ${ }^{2,3}$ \\ Michael B Lensing ${ }^{4}$ \\ Kirsten Rasmussen ${ }^{5,6}$ \\ 'Department of Østmarka, \\ St Olav's Hospital, ${ }^{2}$ Department of \\ Neuroscience, Norwegian University \\ of Science and Technology, Trondheim, \\ ${ }^{3}$ Department of Psychiatry, Helse \\ Nord-Trondelag Hospital Trust, \\ Kirkegata, Levanger, ${ }^{4} \mathrm{NevSom}$, \\ Norwegian Center of Expertise for \\ Neurodevelopmental Disorders and \\ Hypersomnias, Women and Children's \\ Division, Oslo University Hospital, \\ Oslo, ${ }^{5}$ St Olav's Hospital, Broset \\ Center for Research and Education \\ in Forensic Psychiatry, Trondheim, \\ ${ }^{6}$ Department of Psychology, \\ Norwegian University of Science and \\ Technology, Trondheim, Norway
}

Background: The manifestation of attention-deficit/hyperactivity disorder (ADHD) among older adults has become an interesting topic of interest due to an increasing number of adults aged 50 years and older ( $\geq 50$ years) seeking assessment for ADHD. Unfortunately, there is a lack of research on ADHD in older adults, and until recently only a few case reports existed.

Method: A systematic search was conducted in the databases Medline/PubMed and PsycINFO in order to identify studies regarding ADHD in adults $\geq 50$ years.

Results: ADHD persists into older ages in many patients, but the prevalence of patients fulfilling the criteria for the diagnosis at age $\geq 50$ years is still unknown. It is reason to believe that the prevalence is falling gradually with age, and that the ADHD symptom level is significantly lower in the age group 70-80 years than the group 50-60 years. There is a lack of controlled studies of ADHD medication in adults $\geq 50$ years, but this review suggests that many patients aged $\geq 50$ years experience beneficial effects of pharmacological treatment. The problem with side effects and somatic complications may rise to a level that makes pharmacotherapy for ADHD difficult after the age of 65 years. Physical assessment prior to initiation of ADHD medication in adults $\geq 50$ years should include a thorough clinical examination, and medication should be titrated with low doses initially and with a slow increase. In motivated patients, different psychological therapies alone or in addition to pharmacotherapy should be considered.

Conclusion: It is essential when treating older adult patients with ADHD to provide good support based on knowledge and understanding of how ADHD symptoms have affected health, quality of life, and function through the life span. Individualized therapy for each elderly patient should be recommended to balance risk-benefit ratio when pharmacotherapy is considered to be a possible treatment.

Keywords: ADHD, adults, older adults, pharmacotherapy, central stimulants

\section{Introduction to ADHD in the older adult population ( $\geq \mathbf{5 0}$ years)}

Attention-deficit/hyperactivity disorder (ADHD) is a heterogeneous neurobiological disorder recognized today as a more dimensional rather than a categorical condition. ${ }^{1-3}$ The neurobiology of ADHD is underscored both by a high level of inheritance ${ }^{4,5}$ and numerous reports of structural and functional neuropathology. ${ }^{6-9}$

Studies show that the symptoms of ADHD persist into adulthood for at least two-third of the patients diagnosed with ADHD in childhood. ${ }^{10}$ The manifestation of ADHD among older adults has become an issue of growing interest due to an increasing number of adults aged 50 years and older ( $\geq 50$ years) seeking assessment for ADHD for the first time. Unfortunately, there is a lack of research on ADHD in adults aged $\geq 50$ years, and until recently only a few case reports existed. ${ }^{11-13}$

The prevalence of ADHD in adults aged $\geq 50$ years is a question yet to be answered. In a large, epidemiological study by Kessler et al, ${ }^{14}$ the prevalence of ADHD in adults
Correspondence: Terje Torgersen Department of Østmarka, St Olav's Hospital, PO Box 3008, 7440 Lade, Trondheim, Norway

Email terje.torgersen@stolav.no
Neuropsychiatric Disease and Treatment 2016:12 79-87 
was estimated to be $4.4 \%$. This important study did not include patients older than 44 years old. In contrast to this, in a European population-based study, 50\% of the study sample was older than 45 years (range: $18-75$ years), and the prevalence of ADHD in this sample was $1.0 \%-2.5 \% .^{15}$

Some recent studies have investigated the prevalence of ADHD in adults aged $\geq 50$ years and found prevalence rates below the previous estimates for adult ADHD ${ }^{16-18}$ (Table 1). In a Dutch epidemiological study, 1,419 adult participants aged 55-85 years were studied. The prevalence of syndromatic ADHD was $2.8 \%$ and symptomatic ADHD was $4.2 \%{ }^{16}$ The results also showed that younger elderly adults (60-70 years) reported more ADHD symptoms than the older group (71-94 years). The Australian PATH Through Life Project also found that older-age adults (68-74 years) reported significantly lower levels of ADHD symptoms as measured by ASRS screener ${ }^{19}$ than middle-aged adults (48-52 years). Approximately $2.2 \%$ of the older-age adults met the suggested cut-off for the Adult ADHD Self-Report Scale (ASRS)screener score that has been linked to a clinical diagnosis of ADHD, versus $6.2 \%$ in the middle-aged group. ${ }^{18}$

In a Swedish population-based study of 2,500 persons aged 65-80 years, the authors found the prevalence of selfrated childhood ADHD to be 3.3\%. ${ }^{17} \mathrm{~A}$ methodological problem in this study is the dependence on retrospectively experienced childhood symptoms recalled 50-70 years later. The risk for recall bias, and both under- and overestimation of symptoms, is probably high. ${ }^{20}$

These three epidemiological studies indicate that the prevalence of ADHD symptoms appears to decline to $1.0 \%-2.8 \%$ in the oldest ages. ${ }^{16-18}$ Some authors discuss the impact of lower life length expectancy in patients with $\mathrm{ADHD},{ }^{21}$ due to greater rates of accidents, substance abuse, mood disorders, and other health issues, resulting in a relative decline of people with ADHD by age. The lack of age-appropriate diagnostic criteria for adult ADHD may also explain some of the apparent decline in ADHD prevalence in older adults, as discussed by several authors. ${ }^{16-18}$ Simon et al discuss in their meta-analysis the problem with validity of $D S M$ criteria for diagnosing adult ADHD and assume that a strict use of the criteria may lead to an underestimation of the prevalence of ADHD in adults. ${ }^{22}$ Another factor is the occurrence of health-related issues in adults aged $\geq 50$ years, making the differential diagnostic assessment related to an ADHD diagnosis difficult. Examples of such issues are mild cognitive impairment (MCI), ${ }^{23}$ dementia, and other neurodegenerative disorders, increasing polypharmacy, sleep disturbances, chronic pain and other physical conditions, and impaired vision and hearing. Despite the lack of research on ADHD in adults aged $\geq 50$ years, and many unanswered questions about prevalence and persistence of ADHD throughout the life span, there is reason to believe that ADHD or residual ADHD persists into middle age and late adulthood in a large number of patients. A number of recent studies from different countries using national registers and prescription databases have shown that a growing number of patients aged $\geq 50$ years are assessed and treated for ADHD worldwide. ${ }^{24-27}$

\section{Procedure}

A systematic search was conducted in the databases Medline/ PubMed and PsycINFO to identify studies regarding ADHD in adults aged $\geq 50$ years. Search terms were "ADHD AND older adults" published up to date. The resulting list of papers was screened to find papers for this review, and the reference lists in the relevant papers were further screened to find other papers of relevance.

\section{How does ADHD affect the older adult patient? ADHD symptoms across the life span}

The core symptoms of ADHD are persisting inattentiveness, impulsivity, and hyperactivity. Despite the persistence of symptoms, the presentation of symptoms will often change over the course of development. The overt signs

Table I Studies regarding the prevalence of ADHD in adults $\geq 50$ years

\begin{tabular}{|c|c|c|c|c|c|c|}
\hline & $\mathbf{N}$ & Age; range (years) & Age; mean (years) & Procedure & Measures & Prevalence of ADHD (\%) \\
\hline Kooij et al ${ }^{15}$ & 1,813 & $18-75$ & - & Interview & ADHD DSM-IV rating scale ${ }^{96}$ & $1.0-2.5$ \\
\hline \multirow[t]{2}{*}{ Michielsen et $\mathrm{al}^{16}$} & 231 & $60-70$ & 71 & Interview & DIVA $2.0^{97}$ & 4.0 \\
\hline & & $7 I-94$ & & & & I.I \\
\hline \multirow[t]{2}{*}{ Das et al ${ }^{18}$} & 1,907 & $48-52$ & 50.7 & Interview & ASRS screener ${ }^{19}$ & 6.2 \\
\hline & $\mathrm{I}, 536$ & $68-74$ & 70.6 & & & 2.2 \\
\hline $\begin{array}{l}\text { Guldberg-Kjar } \\
\text { and Johansson }\end{array}$ & 1,599 & $65-80$ & 72.0 & $\begin{array}{l}\text { Questionnaire } \\
\text { by postal mail }\end{array}$ & WURS $^{98}$ & 3.3 \\
\hline
\end{tabular}

Abbreviations: ASRS, Adult ADHD Self-Report Scale; ADHD, attention-deficit/hyperactivity disorder; DIVA, Diagnostic Interview ADHD in adults. Second Edition; DSM-IV, Diagnostic and Statistical Manual of Mental Disorders, Fourth Edition; WURS, Wender Utah Rating Scale. 
of hyperactivity and impulsivity in children with ADHD will often decline with increasing age, while symptoms of inattentiveness often will continue unchanged. ${ }^{28}$ The motor hyperactivity in children with ADHD is in adults often replaced by an "inner" hyperactivity in the form of restlessness, excessive fidgeting and talking, inability to relax, and difficulty to sit quietly for long periods. Impulsivity in adulthood may appear as outbursts of anger, impatience, careless driving, and making decisions without thinking. Inattention will manifest as disorganization, forgetfulness, poor performance in planning and completion of tasks, task shifting, and time management. Because of this developmental change in symptom expression, many adults will not fully exhibit the criteria for the diagnosis, while still remaining significantly impaired. ${ }^{29,30}$

In addition to the core symptoms, ADHD in adults is strongly associated with emotional dysregulation (ED). ${ }^{31-33}$ The concept of ED includes symptoms such as increased irritability, low tolerance for frustration and stress, and emotional lability. Recent research indicates, however, that ED is not as specific for ADHD as previously assumed. ${ }^{34}$

\section{Comorbidity}

ADHD in all ages is associated with the presence of psychiatric comorbidity ${ }^{35-38}$ Studies have shown that comorbidity can have a negative impact on treatment outcome in ADHD across the life span. ${ }^{36,39-41}$ Recent studies indicate that psychiatric comorbidity mostly occurs during childhood and adolescence, and more seldom have onset after the age of 20 years..$^{38} \mathrm{~A}$ recent study by Rasmussen et $\mathrm{al}^{42}$ suggests that living longer without receiving central stimulant (CS) treatment may lead to an increase in comorbid psychiatric problems. The comorbid disorders most strongly associated with adult ADHD are anxiety disorders, mood disorders, antisocial personality disorder, and substance use disorders. . $^{36,38,43-46}$

Most studies of comorbidity in adult ADHD are done in samples of young adults up to 40 years. The developmental alteration of comorbid disorders into middle-aged and older samples is poorly understood. We have identified only a few studies presenting data on comorbidity in samples of adults aged $\geq 50$ years. ${ }^{47-49}$ A Dutch study, with average sample age 71 years (range: 60-94 years), found that participants with ADHD had more depressive and anxiety symptoms than participants without ADHD. ${ }^{48}$ In another paper presenting data from the same study, the authors found that older adults with ADHD had significantly lower self-esteem and sense of mastery, and higher levels of neuroticism and social inadequacy, than older adults without ADHD. Self-esteem and sense of mastery partly explained the association between ADHD and depressive symptoms. ${ }^{50}$ Semeijn et a ${ }^{51,52}$ found that the risk of depression in older adults with ADHD was partly explained by serious conflicts and adverse life events. In this study, lower cognitive functioning was also explained by depressive symptoms.

In a sample of adults aged $\geq 50$ years with ADHD from Norway (mean age: 55.7 years), $46.7 \%$ of the participants reported psychiatric comorbidity, depression $36.7 \%$, anxiety $26.5 \%$, and bipolar disorder $24.5 \%{ }^{53}$ The sample was recruited from the national ADHD organization, and not necessarily representative for adults aged $\geq 50$ years with ADHD. In a small study of 27 patients from the US, recruited from psychiatrists in private practice, $63 \%$ of the participants reported having other mental health conditions, depression $54 \%$, anxiety $42 \%$, and bipolar disorder $8 \% .{ }^{47}$

In the older population, the prevalence of dementia increases steadily with advancing age. $\mathrm{MCI}^{52}$ is a diagnosis designed as a predictor of prodromal degenerative dementia, and its prevalence in the geriatric population is estimated to $16 \%{ }^{23} \mathrm{MCI}$ includes cognitive problems in older ages that do not meet the criteria for dementia, and results in no or minimal functional impairment. ${ }^{54}$ In a review by Ivanchak et $\mathrm{al},{ }^{23}$ the authors discuss the role of ADHD as a predisposing factor for $\mathrm{MCI}$ and more manifest degenerative disease in late life, but conclude that such an association is less than convincing. On the contrary, a clinical study from Argentina found an association between childhood ADHD and dementia with Lewy bodies, but not with Alzheimer's disease. The authors have no explanation for this association between ADHD and dementia with Lewy bodies, but discuss the role of dopaminergic dysfunction in both diseases. ${ }^{55}$

There has been a growing interest in somatic comorbidity in ADHD. A number of somatic diseases have been found to have an association to ADHD in children, adolescence, and young adults, such as obesity, musculoskeletal pain, asthma, and allergy. ${ }^{56-58}$ The association between somatic diseases and ADHD in older adults is largely unknown. In Lensing et al's study $^{53}$ of 149 adults aged $\geq 50$ years with ADHD, 46.6\% reported co-occurring somatic disorders. Hypothyroidism $20.6 \%$, hypertension $19.1 \%$, fibromyalgia $16.2 \%$, and arthritis $16.2 \%$ were the most common disorders. Another finding from the same sample showed that $73.7 \%$ of the patients reported moderate-to-severe pain/discomfort on EuroQoL, ${ }^{59}$ in comparison to $43.8 \%$ in the age- and sex-matched population norm. ${ }^{49}$ In a small sample of eleven clinically recruited patients with mean age 61.6 years, $55 \%$ had somatic disorders like hypertension, type 2 diabetes, and ischemic heart disease. ${ }^{60} \mathrm{In}$ 
a study comparing 23 older adults with 208 controls without ADHD, the authors could not find significant differences in a number of somatic diseases, like chronic lung disease, cardiovascular disease, diabetes, arthritis, and cancer. ${ }^{48}$ In an adjusted regression analysis, they found, however, that the number of ADHD symptoms was associated with the presence of chronic lung disease, cardiovascular disease, and number of somatic diseases. Interestingly, the authors found no association between ADHD and an unhealthy lifestyle.

\section{Impairment}

A number of controlled follow-up studies have shown that ADHD in young adults is associated with impairment in several life domains, such as academic, occupational, and social functioning. ${ }^{61-63}$ In a study of 148 adults aged $\geq 50$ years with ADHD (mean age 55.7 years), compared to an age group-matched reference sample, the ADHD patients were significantly more often single ( $41.5 \%$ versus $25.2 \%)$ and less frequently employed (48.8\% versus $69.2 \%) .{ }^{49}$ Surprisingly, in this study the level of education was not different between groups. The study showed that adults aged $\geq 50$ years with ADHD reported significantly reduced quality of life compared to population norms. A Dutch study that recruited patients with a mean age 68 years also found a significantly higher level of divorced/never married in the ADHD group compared to the non-ADHD group (26.1\% versus $10.1 \%) .{ }^{64}$ They also found that ADHD was associated with having fewer family members in their network and experiencing emotional loneliness. Because of the presence of only a few studies, relatively small samples, and different age groups, it is not possible to draw definitive conclusions about impairment in adults aged $\geq 50$ years with ADHD. However, the results indicate that the negative impact of ADHD seems to persist into late adulthood. In a paper based on a study of 24 clinically referred older adults with ADHD, Brod et $\mathrm{al}^{47}$ found that the quality of life suffers from the accumulated negative impact of ADHD symptoms and impairments on their professional, economic, social, and emotional well-being. At the same time, none of the patients in this study indicated worsening of ADHD symptoms with aging, and some stated that living with ADHD got easier with age. Similar findings are also described by the patients in the paper by Henry and Jones. ${ }^{11}$

\section{Pharmacological treatment of ADHD in older adults}

Older adults are underrepresented in pharmacokinetic and pharmacodynamic studies, leading to a lack of knowledge and understanding of pharmacologic treatment in this age group. ${ }^{65,66}$ Very few studies regarding pharmacotherapy of ADHD in older adults are published. ${ }^{53,67}$ We know, however, that the problem with polypharmacy and drugdrug interactions is growing in older adults. With aging, a series of changes occur that modify the pharmacokinetics and pharmacodynamics of psychotropic medication. This may influence the efficacy, tolerability, and safety of any psychopharmacologic treatment. ${ }^{68}$ Pharmacological treatment in older adults should generally follow similar guidelines as with younger patients except that drug dosing and speed of titration should be slower and start lower. Side effect profile is a greater consideration than with younger patients. ${ }^{69}$ In a paper by Sajatovic, ${ }^{69}$ the author listed some key clinical issues among older adults prescribed psychotropic medication; they generally have a reduced capacity to metabolize drugs, and are relatively sensitive to medication-associated side effects.

Pharmacological treatment has been the cornerstone in management of ADHD for decades, and numerous studies have proven its efficacy in reducing ADHD symptoms in all age groups. ${ }^{70-72} \mathrm{CS}$ are recommended as first-line treatment, and have a well-documented short-term effect on symptoms. Little is known about effects on long-term outcomes like mortality, symptom level, impairment, and quality of life. ${ }^{73}$ A few open and naturalistic studies indicate a long-term beneficial effect from CS therapy in adults, but there is a lack of controlled studies lasting more than a few weeks. ${ }^{73-76}$

In our search we could not find controlled studies of pharmacologic treatment of ADHD in the age group $\geq 50$ years, but a few naturalistic studies have been published (Table 2). In 2011, Manor et al ${ }^{60}$ described eleven adults aged 55+ diagnosed with ADHD for the first time. Mean age was 62 years, and male-female ratio 9:2. All patients were treated with methylphenidate (MPH) and followed for at least 2 months with moderate doses (eight patients tried MPH immediate release in daily doses between 20 and $35 \mathrm{mg}$, two patients MPH long acting agents $60-80 \mathrm{mg}$, and one patient tried osmotic-release oral system MPH 72-108 mg). At follow-up, only two patients had stopped using the medication, and eight patients showed significant improvement on the test of variables of attention. ${ }^{77}$ No adverse events were reported. The authors concluded that this group of middle-aged and older ADHD patients had a similar response to MPH as younger adults.

Brod et $\mathrm{al}^{47}$ explored the burden of illness and impact of ADHD on quality of life in 24 patients with mean age 66 years. Information was collected by telephone interviews. All patients had been taking ADHD medication at some point after being diagnosed. Most patients reported a beneficial effect of medication, and found themselves being able to be more organized, understand written text better, and be more focused. Some patients reported medication side effects, such 
Table 2 Naturalistic studies of pharmacological treatment of ADHD in adults $\geq 50$ years

\begin{tabular}{|c|c|c|c|c|}
\hline Author & $\mathbf{N}$ & $\begin{array}{l}\text { Mean age } \\
\text { (years) }\end{array}$ & Pharmacologic treatment & Doses \\
\hline Manor et $a^{60}$ & II & 62 & $\begin{array}{l}\text { All patients treated with MPH and at least } 2 \text { months, eight } \\
\text { showed improvement }\end{array}$ & $\begin{array}{l}\text { MPH IM 20-35 mg }(\mathrm{N}=8) \\
\text { MPH LA 60-80 mg }(\mathrm{N}=2) \\
\text { OROS MPH } 72-108 \mathrm{mg}(\mathrm{N}=\mathrm{I})\end{array}$ \\
\hline Brod et al ${ }^{47}$ & 24 & 66 & $\begin{array}{l}\text { All patients had been taking ADHD medication at some time, } \\
\text { and most patients reported a beneficial effect of medication }\end{array}$ & \\
\hline Lensing et $\mathrm{al}^{53}$ & 149 & 56 & $\begin{array}{l}88 \% \text { of the participants had been treated with ADHD } \\
\text { medication at some time following diagnosis, and } 64 \% \text { used } \\
\text { some type of ADHD medication } 5 \text { years after diagnosis }\end{array}$ & $\begin{array}{l}\text { Self-reported mean daily dose: MPH } 54.1 \mathrm{mg} \\
\text { (range: 8-135 mg) Amphetamine } 29.5 \mathrm{mg} \\
\text { (range: } 4-50 \mathrm{mg} \text { ) }\end{array}$ \\
\hline
\end{tabular}

Abbreviations: ADHD, attention-deficit/hyperactivity disorder; MPH IM, methylphenidate immediate release; MPH LA, methylphenidate long acting; MPH, methylphenidate; OROS, osmotic-release oral system.

as nausea, sleepiness, insomnia, overexcitement, headache, and anxiety.

Recently, Lensing et $\mathrm{al}^{53}$ presented the results from a study of 149 members of a national ADHD patient organization aged $\geq 50$ years. Mean age was 55.8 years, and mean age diagnosed with ADHD was 50.3 years. Approximately $88 \%$ of the participants had been treated with ADHD medication at some time following diagnosis, and currently $64 \%$ used some type of ADHD medication. The self-reported mean daily dose for MPH was $54.1 \mathrm{mg}$ (range: $8-135 \mathrm{mg}$ ) and for amphetamine was $29.5 \mathrm{mg}$ (range: 4-50 mg). The currently medicated group was compared with a group that had stopped medication and a medication-naïve group. The only significant difference between groups was that the group currently on medication reported better attention when compared to 10 years ago than the nonmedicated groups. The mean score on the ASRS screener was not significantly different between the groups in this study. The most important finding is probably that a majority of the participants received ADHD medication for longer periods and in doses comparable to the doses given to younger adults.

We were unable to identify any studies addressing treatment with atomoxetine for ADHD in adults aged $\geq 50$ years, but one relevant paper presented data from a post hoc analysis using data from two double-blind, placebo-controlled clinical trials of atomoxetine in adult ADHD. Data from young adults (mean age 21.7 years) were compared with data from older adults (mean age 43.4 years) and larger effect sizes for the younger group than the older group was found, as measured by the Conner's Adult ADHD Rating Scale ${ }^{78}$ (0.797 versus 0.326). The authors argue that this difference is primarily due to greater variability of response in older patients. ${ }^{79}$ When looking at side effects, the only significant difference between groups was more sexual side effects in the older group.

The papers described in this review show that CS treatment is used in adults aged $\geq 50$ years in different countries like US, Israel, and Norway in doses comparable to doses used in younger adults. In these naturalistic studies, the patients report beneficial effects of medication, but we do not know the effect sizes due to the lack of controlled study design. There is, however, some data indicating a reduction of the effect of CS in older ages. Several studies have shown that higher level of ADHD symptoms at baseline predict better efficacy of CS treatment in adult ADHD. ${ }^{80-82}$ At the same time, the results from the Australian PATH Through Life Project ${ }^{18}$ showed that older-age adults (68-74 years) reported significantly lower levels of ADHD symptoms as measured by ASRS screener than middle-aged adults (48-52 years). This decline in ADHD symptoms may lead to a diminishing efficacy of medication in older ages. Another finding substantiating a reduced efficacy with age is a study by Volkow et al, ${ }^{83}$ showing an age-related decline in dopamine transporter capacity. The atomoxetine study by Durell et $\mathrm{al}^{79}$ showing lower effect sizes in the middle-aged group (mean age 43.4 years) than in the younger adults may point in the same direction, suggesting that age may be a predictor of reduced efficacy of pharmacological treatment in adult ADHD. Further research is needed in this field.

In addition to the issue of efficacy of ADHD medication in adults aged $\geq 50$ years, there is a concern about side effects. The most common side effects of CS are reduced appetite, nausea, dry mouth, insomnia, anxiety, and headache. The geriatric population (age $>65$ years) may, due to a changing physiology, be predisposed to adverse events, and relatively harmless side effects may impact the individual more negatively than in younger adults. Weight loss because of reduced appetite is probably more harmful for the health in an elderly person, and insomnia as a side effect may add to the higher prevalence of sleep problems we find in the geriatric population. In one study of treatment with MPH for apathy in Alzheimer's disease, two patients experienced serious adverse events consisting of delusions, agitation, anger, irritability, and insomnia. ${ }^{84}$ Another safety concern when treating older persons with CS is the risk to exacerbate an attack of glaucoma. 
There is a concern that CS treatment in ADHD may be associated with adverse cardiovascular events, but the findings are mixed. ${ }^{85}$ Westover and Halm, ${ }^{85}$ in their review, state that studies of adults show an increased risk for transient ischemic attacks and sudden death, but interpretation is limited mostly due to methodological problems. Recently a large, Danish nationwide cohort study found that the use of CS increased the risk for cardiovascular adverse events in children and adolescents. Cardiovascular adverse events were rare, but twice as likely in CS users compared to nonusers. ${ }^{86}$ Despite a low risk in most patients, the clinicians must take precautions when it comes to middle-aged and older adults, because of the general increased risk of cardiovascular disease in this population. Older patients may also be more vulnerable to the increased blood pressure and the increased heart rate often experienced by patients using CS. Physical assessment prior to initiation of ADHD medication in adults aged $\geq 50$ years should include a thorough clinical examination, medical history, and electrocardiogram. Heart rate, blood pressure, and weight should be taken before and during treatment.

\section{Psychological treatment and support}

Although pharmacological treatment is generally considered the first choice of treatment in adults with ADHD, it is rarely sufficient. In addition to the limiting factors discussed above, there are more general factors which may reduce the effect of drug therapy, like poor compliance to medication and lack of continuity of medication. ${ }^{87}$ In addition, the high prevalence of comorbid psychiatric disorders, inefficient compensatory strategies, and maladaptive thoughts may reduce the potential for drug efficacy in adult ADHD.

Throughout the last 10-15 years, several studies reporting effects of psychological treatment on adult ADHD have been published. We identified several controlled studies of psychotherapy for adult ADHD in our search, but none of the identified studies were specifically investigating psychological treatment in adults aged $\geq 50$ years. However, Solanto et al ${ }^{88}$ investigated the efficacy of meta-cognitive therapy (MCT) in a group format for adults with a diagnosis of ADHD aged between 18 and 65 years, comparing MCT with supportive therapy. The participants $(\mathrm{N}=88)$ were stratified by ADHD medication and randomized to either MCT or supportive therapy. MCT is described as an intervention where cognitive behavioral principles are employed to provide contingent self-reward, skills in dismantling complex tasks into manageable units, and sustaining motivation. Participants were assigned to either MCT $(n=45)$ or supportive therapy $(n=43)$ in a group format during a 12 -week treatment or supportive intervention. Participants in the MCT condition achieved significant greater improvement in attention and memory scores on Conner's Adult ADHD Rating Scales subscale ${ }^{78}$ compared to the supportive treatment group.

In a blinded randomized, placebo-controlled, parallel-group study, Weiss et $\mathrm{al}^{89}$ compared individual cognitive behavioral therapy (CBT) and Dexedrine (CBT/DEX) with CBT and placebo (CBT/PLB) in a sample with age ranging between 18 and 66 years. The therapy was administered individually for nine sessions. ADHD symptoms were measured by the investigator administered ADHD-Rating Scale-Investigator. ${ }^{78}$ There were no statistical differences between CBT/DEX and CBT/PLB at baseline or in follow-up, and both groups showed robust improvement over time. Results for the Sheehan Disability Scale ${ }^{90}$ showed that the CBT/DEX group improved in functioning by week 15 and that this improvement sustained at week 20. The CBT/PLB group also showed improvement in functioning at week 15 , but this improvement attenuated slightly at week 20 .

In addition to these two studies including adults aged $\geq 50$ years, several studies are published showing efficacy of different forms of psychotherapy in younger adults with ADHD. ${ }^{91-95}$ We assume that these therapies will be useful also in adults $\geq 50$ years, as long as they have normal cognitive function, sufficiently remaining senses, and of course, are motivated.

Despite the fact that none of the studies had a particular focus on adults aged $\geq 50$ years, several studies have shown that older adults are treated with psychological therapies in different countries. ${ }^{53,88}$ In psychological therapy with adults aged $\geq 50$ years, common life-stage issues should be included in therapy if relevant, such as physical illness, retirement and job loss, loss of societal and financial status, and changes in interpersonal relationships due to illness or death.

\section{Conclusion}

The papers included in this review indicate that ADHD persists into older age in many patients, but the prevalence of patients fulfilling the criteria for the diagnosis at ages $\geq 50$ years is still unknown. It is reason to believe that the prevalence is falling gradually with age and that the ADHD symptom level is significantly lower in the age group 70-80 years than the group 50-60 years. Both the diagnostic assessment and treatment of ADHD may be more difficult for the clinician in older patients, as the clinical picture gets more complicated when age-related health issues appear in middle-aged and older adults with ADHD. There is a lack of controlled studies of ADHD medication in adults aged $\geq 50$ years, but this review suggests that many patients aged $\geq 50$ years experience beneficial effects of pharmacological treatment with minimal side effects. It is, 
however, reason to believe that the chance of getting a satisfactory effect is lower after reaching geriatric age (65 years and older) for most patients. The problem with side effects and somatic complications may also rise to a level that makes pharmacotherapy for ADHD difficult after the age of 65 years. Given these aspects, individualized therapy for each elderly patient should be recommended to balance risk-benefit ratio when pharmacotherapy is considered to be a possible treatment. Physical assessment prior to initiation of ADHD medication in adults aged $\geq 50$ years should include a thorough clinical examination, and medication should be titrated with low doses initially and a slow increase. In motivated patients, different psychological therapies alone or in addition to pharmacotherapy should be considered. It is essential when treating older adult ADHD patients to provide good support based on knowledge and understanding of how ADHD symptoms have affected health, quality of life, and function through the life span.

\section{Disclosure}

The authors report no conflicts of interest in this work.

\section{References}

1. Shaw P, Gilliam M, Liverpool M, et al. Cortical development in typically developing children with symptoms of hyperactivity and impulsivity: support for a dimensional view of attention deficit hyperactivity disorder. Am J Psychiatry. 2011;168(2):143-151.

2. Lubke GH, Hudziak JJ, Derks EM, van Bijsterveldt TC, Boomsma DI. Maternal ratings of attention problems in ADHD: evidence for the existence of a continuum. J Am Acad Child Adolesc Psychiatry. 2009;48(11):1085-1093.

3. Hoogman M, Rijpkema M, Janss L, et al. Current self-reported symptoms of attention deficit/hyperactivity disorder are associated with total brain volume in healthy adults. PLoS One. 2012;7(2):e31273.

4. Franke B, Neale BM, Faraone SV. Genome-wide association studies in ADHD. Hum Genet. 2009;126(1):13-50.

5. Lee SH, Ripke S, Neale BM, et al. Genetic relationship between five psychiatric disorders estimated from genome-wide SNPs. Nat Genet. 2013;45(9):984-994.

6. Valera EM, Faraone SV, Murray KE, Seidman LJ. Meta-analysis of structural imaging findings in attention-deficit/hyperactivity disorder. Biol Psychiatry. 2007;61(12):1361-1369.

7. Rubia K, Overmeyer S, Taylor E, et al. Hypofrontality in attention deficit hyperactivity disorder during higher-order motor control: a study with functional MRI. Am J Psychiatry. 1999;156(6):891-896.

8. Greven CU, Bralten J, Mennes M, et al. Developmentally stable wholebrain volume reductions and developmentally sensitive caudate and putamen volume alterations in those with attention-deficit/hyperactivity disorder and their unaffected siblings. JAMA Psychiatry. 2015; 72(5):490-499.

9. van RD, Hoekstra PJ, Mennes M, et al. Distinguishing adolescents with ADHD from their unaffected siblings and healthy comparison subjects by neural activation patterns during response inhibition. Am J Psychiatry. 2015;172(7):674-683.

10. Faraone SV, Biederman J, Mick E. The age-dependent decline of attention deficit hyperactivity disorder: a meta-analysis of follow-up studies. Psychol Med. 2006;36(2):159-165.

11. Henry E, Jones SH. Experiences of older adult women diagnosed with attention deficit hyperactivity disorder. J Women Aging. 2011;23(3): 246-262.
12. da Silva MA, Louza M. Case of a 67-year-old woman diagnosed with ADHD successfully treated with methylphenidate. $J$ Atten Disord. 2008;11(6):623.

13. Biederman J. A 55-year-old man with attention-deficit/hyperactivity disorder. JAMA. 1998;280(12):1086-1092.

14. Kessler RC, Adler L, Barkley R, et al. The prevalence and correlates of adult ADHD in the United States: results from the National Comorbidity Survey Replication. Am J Psychiatry. 2006;163(4):716-723.

15. Kooij JJ, Buitelaar JK, van den Oord EJ, Furer JW, Rijnders CA, Hodiamont PP. Internal and external validity of attention-deficit hyperactivity disorder in a population-based sample of adults. Psychol Med. 2005;35(6):817-827.

16. Michielsen M, Semeijn E, Comijs HC, et al. Prevalence of attentiondeficit hyperactivity disorder in older adults in the Netherlands. Br J Psychiatry. 2012;201(4):298-305.

17. Guldberg-Kjar T, Johansson B. Old people reporting childhood AD/ $\mathrm{HD}$ symptoms: retrospectively self-rated $\mathrm{AD} / \mathrm{HD}$ symptoms in a population-based Swedish sample aged 65-80. Nord J Psychiatry. 2009;63(5):375-382.

18. Das D, Cherbuin N, Easteal S, Anstey KJ. Attention deficit/hyperactivity disorder symptoms and cognitive abilities in the late-life cohort of the PATH through life study. PLoS One. 2014;9(1):e86552.

19. Kessler RC, Adler L, Ames M, et al. The World Health Organization Adult ADHD Self-Report Scale (ASRS): a short screening scale for use in the general population. Psychol Med. 2005;35(2):245-256.

20. Mannuzza S, Klein RG, Klein DF, Bessler A, Shrout P. Accuracy of adult recall of childhood attention deficit hyperactivity disorder. Am J Psychiatry. 2002;159(11):1882-1888.

21. Dalsgaard S, Ostergaard SD, Leckman JF, Mortensen PB, Pedersen MG. Mortality in children, adolescents, and adults with attention deficit hyperactivity disorder: a nationwide cohort study. Lancet. 2015; 385(9983):2190-2196.

22. Simon V, Czobor P, Balint S, Meszaros A, Bitter I. Prevalence and correlates of adult attention-deficit hyperactivity disorder: meta-analysis. Br J Psychiatry. 2009;194(3):204-211.

23. Ivanchak N, Fletcher K, Jicha GA. Attention-deficit/hyperactivity disorder in older adults: prevalence and possible connections to mild cognitive impairment. Curr Psychiatry Rep. 2012;14(5):552-560.

24. Kristiansen CB, Shanmuganathan JW, Gustafsson LN, Lokke KP, Munk-Jorgensen P. Increasing incidence and diagnostic instability in adult attention-deficit hyperactivity disorder nationwide between 1995 and 2012. Atten Defic Hyperact Disord. 2015;7(2):151-156.

25. Geirs DP, Pottegard A, Halldorsson M, Zoega H. A nationwide study of attention-deficit/hyperactivity disorder drug use among adults in Iceland 2003-2012. Basic Clin Pharmacol Toxicol. 2014;115(5):417-422.

26. Pottegard A, Bjerregaard BK, Glintborg D, Hallas J, Moreno SI. The use of medication against attention deficit hyperactivity disorder in Denmark: a drug use study from a national perspective. Eur J Clin Pharmacol. 2012;68(10):1443-1450.

27. McCarthy S, Wilton L, Murray ML, Hodgkins P, Asherson P, Wong IC. The epidemiology of pharmacologically treated attention deficit hyperactivity disorder (ADHD) in children, adolescents and adults in UK primary care. BMC Pediatr. 2012;12:78.

28. Biederman J, Mick E, Faraone SV. Age-dependent decline of symptoms of attention deficit hyperactivity disorder: impact of remission definition and symptom type. Am J Psychiatry. 2000;157(5):816-818.

29. Turgay A, Goodman DW, Asherson P, et al. Lifespan persistence of ADHD: the life transition model and its application. J Clin Psychiatry. 2012;73(2):192-201.

30. Gibbins C, Weiss M. Clinical recommendations in current practice guidelines for diagnosis and treatment of ADHD in adults. Curr Psychiatry Rep. 2007;9(5):420-426.

31. Corbisiero S, Stieglitz RD, Retz W, Rosler M. Is emotional dysregulation part of the psychopathology of ADHD in adults? Atten Defic Hyperact Disord. 2013;5(2):83-92.

32. Retz W, Stieglitz RD, Corbisiero S, Retz-Junginger P, Rosler M. Emotional dysregulation in adult ADHD: what is the empirical evidence? Expert Rev Neurother. 2012;12(10):1241-1251. 
33. Reimherr FW, Marchant BK, Strong RE, et al. Emotional dysregulation in adult ADHD and response to atomoxetine. Biol Psychiatry. 2005; 58(2):125-131.

34. Asherson P, Young AH, Eich-Hochli D, Moran P, Porsdal V, Deberdt W. Differential diagnosis, comorbidity, and treatment of attention-deficit/hyperactivity disorder in relation to bipolar disorder or borderline personality disorder in adults. Curr Med Res Opin. 2014; 30(8):1657-1672.

35. Biederman J, Wilens T, Mick E, Milberger S, Spencer TJ, Faraone SV. Psychoactive substance use disorders in adults with attention deficit hyperactivity disorder (ADHD): effects of ADHD and psychiatric comorbidity. Am J Psychiatry. 1995;152(11):1652-1658.

36. Torgersen T, Gjervan B, Rasmussen K, Vaaler A, Nordahl HM. Prevalence of comorbid substance use disorder during long-term central stimulant treatment in adult ADHD. Atten Defic Hyperact Disord. 2013;5(1):59-67.

37. Rasmussen K, Levander S. Untreated ADHD in adults: are there sex differences in symptoms, comorbidity, and impairment? J Atten Disord. 2009;12(4):353-360.

38. Klein RG, Mannuzza S, Olazagasti MA, et al. Clinical and functional outcome of childhood attention-deficit/hyperactivity disorder 33 years later. Arch Gen Psychiatry. 2012;69(12):1295-1303.

39. Retz W, Retz-Junginger P. Prediction of methylphenidate treatment outcome in adults with attention-deficit/hyperactivity disorder (ADHD). Eur Arch Psychiatry Clin Neurosci. 2014;264(Suppl 1):S35-S43.

40. Molina BS, Hinshaw SP, Eugene AL, et al. Adolescent substance use in the multimodal treatment study of attention-deficit/hyperactivity disorder (ADHD) (MTA) as a function of childhood ADHD, random assignment to childhood treatments, and subsequent medication. $J$ Am Acad Child Adolesc Psychiatry. 2013;52(3):250-263.

41. Molina BS, Hinshaw SP, Swanson JM, et al. The MTA at 8 years: prospective follow-up of children treated for combined-type ADHD in a multisite study. J Am Acad Child Adolesc Psychiatry. 2009;48(5): 484-500.

42. Rasmussen K, Palmstierna T, Levander S. Differences in psychiatric problems and criminality between individuals treated with central stimulants before and after adulthood. J Atten Disord. Epub March 20, 2015.

43. Biederman J, Faraone SV, Spencer T, et al. Patterns of psychiatric comorbidity, cognition, and psychosocial functioning in adults with attention deficit hyperactivity disorder. Am J Psychiatry. 1993;150(12): $1792-1798$.

44. Kooij JJ, Burger H, Boonstra AM, Van der Linden PD, Kalma LE, Buitelaar JK. Efficacy and safety of methylphenidate in 45 adults with attention-deficit/hyperactivity disorder. A randomized placebo-controlled double-blind cross-over trial. Psychol Med. 2004; 34(6):973-982.

45. Sobanski E. Psychiatric comorbidity in adults with attention-deficit/ hyperactivity disorder (ADHD). Eur Arch Psychiatry Clin Neurosci. 2006;256(Suppl 1):i26-i31.

46. Mannuzza S, Klein RG, Bessler A, Malloy P, LaPadula M. Adult psychiatric status of hyperactive boys grown up. Am J Psychiatry. 1998; 155(4):493-498.

47. Brod M, Schmitt E, Goodwin M, Hodgkins P, Niebler G. ADHD burden of illness in older adults: a life course perspective. Qual Life Res. 2012;21(5):795-799.

48. Michielsen M, Comijs HC, Semeijn EJ, Beekman AT, Deeg DJ, Sandra Kooij JJ. The comorbidity of anxiety and depressive symptoms in older adults with attention-deficit/hyperactivity disorder: a longitudinal study. J Affect Disord. 2013;148(2-3):220-227.

49. Lensing MB, Zeiner P, Sandvik L, Opjordsmoen S. Quality of life in adults aged 50+ with ADHD. J Atten Disord. 2015;19(5):405-413.

50. Michielsen M, Comijs HC, Semeijn EJ, Beekman AT, Deeg DJ, Kooij JJ. Attention deficit hyperactivity disorder and personality characteristics in older adults in the general Dutch population. Am J Geriatr Psychiatry. 2014;22(12):1623-1632.
51. Semeijn EJ, Korten NC, Comijs HC, et al. No lower cognitive functioning in older adults with attention-deficit/hyperactivity disorder. Int Psychogeriatr. 2015;27(9):1467-1476.

52. Semeijn EJ, Comijs HC, Kooij JJ, Michielsen M, Beekman AT, Deeg DJ. The role of adverse life events on depression in older adults with ADHD. J Affect Disord. 2015;174:574-579.

53. Lensing MB, Zeiner P, Sandvik L, Opjordsmoen S. Psychopharmacological treatment of ADHD in adults aged 50+: an empirical study. J Atten Disord. 2015;19(5):380-389.

54. Winblad B, Palmer K, Kivipelto M, et al. Mild cognitive impairment beyond controversies, towards a consensus: report of the International Working Group on Mild Cognitive Impairment. J Intern Med. 2004; 256(3):240-246.

55. Golimstok A, Rojas JI, Romano M, Zurru MC, Doctorovich D, Cristiano E. Previous adult attention-deficit and hyperactivity disorder symptoms and risk of dementia with Lewy bodies: a case-control study. Eur J Neurol. 2011;18(1):78-84.

56. Cortese S, Moreira-Maia CR, St Fleur D, Morcillo-Penalver C, Rohde LA, Faraone SV. Association between ADHD and obesity: a systematic review and meta-analysis. Am J Psychiatry. Epub August 28, 2015.

57. Catal F, Topal E, Soylu N, et al. Psychiatric disorders and symptoms severity in preschool children with atopic eczema. Allergol Immunopathol (Madr). Epub August 3, 2015.

58. Treister R, Eisenberg E, Demeter N, Pud D. Alterations in pain response are partially reversed by methylphenidate (Ritalin) in adults with attention deficit hyperactivity disorder (ADHD). Pain Pract. 2015;15(1):4-11.

59. Rabin R, de CF. EQ-5D: a measure of health status from the EuroQol Group. Ann Med. 2001;33(5):337-343.

60. Manor I, Rozen S, Zemishlani Z, Weizman A, Zalsman G. When does it end? Attention-deficit/hyperactivity disorder in the middle aged and older populations. Clin Neuropharmacol. 2011;34(4):148-154.

61. Barkley RA, Fischer M, Smallish L, Fletcher K. Young adult outcome of hyperactive children: adaptive functioning in major life activities. J Am Acad Child Adolesc Psychiatry. 2006;45(2):192-202.

62. Biederman J, Petty CR, Monuteaux MC, et al. Adult psychiatric outcomes of girls with attention deficit hyperactivity disorder: 11-year follow-up in a longitudinal case-control study. Am J Psychiatry. 2010; 167(4):409-417.

63. Mannuzza S, Klein RG, Bessler A, Malloy P, Hynes ME. Educational and occupational outcome of hyperactive boys grown up. $J$ Am Acad Child Adolesc Psychiatry. 1997;36(9):1222-1227.

64. Michielsen M, Comijs HC, Aartsen MJ, et al. The relationships between ADHD and social functioning and participation in older adults in a population-based study. J Atten Disord. 2015;19(5):368-379.

65. Mangoni AA, Jansen PA, Jackson SH. Under-representation of older adults in pharmacokinetic and pharmacodynamic studies: a solvable problem? Expert Rev Clin Pharmacol. 2013;6(1):35-39.

66. Reeve E, Wiese MD, Mangoni AA. Alterations in drug disposition in older adults. Expert Opin Drug Metab Toxicol. 2015;11(4):491-508.

67. Wilens TE, Morrison NR, Prince J. An update on the pharmacotherapy of attention-deficit/hyperactivity disorder in adults. Expert Rev Neurother. 2011;11(10):1443-1465.

68. Alamo C, Lopez-Munoz F, Garcia-Garcia P, Garcia-Ramos S. Risk-benefit analysis of antidepressant drug treatment in the elderly. Psychogeriatrics. 2014;14(4):261-268.

69. Sajatovic M. Treatment of bipolar disorder in older adults. Int J Geriatr Psychiatry. 2002;17(9):865-873.

70. Faraone SV, Glatt SJ. A comparison of the efficacy of medications for adult attention-deficit/hyperactivity disorder using meta-analysis of effect sizes. J Clin Psychiatry. 2010;71(6):754-763.

71. Koesters M, Becker T, Kilian R, Fegert JM, Weinmann S. Limits of meta-analysis: methylphenidate in the treatment of adult attention-deficit hyperactivity disorder. J Psychopharmacol. 2009;23(7): 733-744. 
72. Torgersen T, Gjervan B, Rasmussen K. Treatment of adult ADHD: is current knowledge useful to clinicians? Neuropsychiatr Dis Treat. 2008;4(1):177-186.

73. Fredriksen M, Halmoy A, Faraone SV, Haavik J. Long-term efficacy and safety of treatment with stimulants and atomoxetine in adult ADHD: a review of controlled and naturalistic studies. Eur Neuropsychopharmacol. 2013;23(6):508-527.

74. Fredriksen M, Dahl AA, Martinsen EW, Klungsoyr O, Haavik J, Peleikis DE. Effectiveness of one-year pharmacological treatment of adult attention-deficit/hyperactivity disorder (ADHD): an open-label prospective study of time in treatment, dose, side-effects and comorbidity. Eur Neuropsychopharmacol. 2014;24(12):1873-1884.

75. Bejerot S, Ryden EM, Arlinde CM. Two-year outcome of treatment with central stimulant medication in adult attention-deficit/ hyperactivity disorder: a prospective study. J Clin Psychiatry. 2010; 71(12):1590-1597.

76. Shaw M, Hodgkins $\mathrm{P}$, Caci H, et al. A systematic review and analysis of long-term outcomes in attention deficit hyperactivity disorder: effects of treatment and non-treatment. BMC Med. 2012;10:99.

77. Greenberg LM, Waldman ID. Developmental normative data on the test of variables of attention (T.O.V.A.). J Child Psychol Psychiatry. 1993;34(6):1019-1030.

78. Conners CK, Erhardt D, Sparrow EP. Conners Adult ADHD Rating Scales, Technical Manual. New York, NY: Multi-Health Systems; 1998.

79. Durell T, Adler L, Wilens T, Paczkowski M, Schuh K. Atomoxetine treatment for ADHD: younger adults compared with older adults. $J$ Atten Disord. 2010;13(4):401-406.

80. Buitelaar JK, Kooij JJ, Ramos-Quiroga JA, et al. Predictors of treatment outcome in adults with ADHD treated with OROS(R) methylphenidate. Prog Neuropsychopharmacol Biol Psychiatry. 2011;35(2):554-560.

81. Ginsberg L, Katic A, Adeyi B, et al. Long-term treatment outcomes with lisdexamfetamine dimesylate for adults with attention-deficit/ hyperactivity disorder stratified by baseline severity. Curr Med Res Opin. 2011;27(6):1097-1107.

82. Torgersen T, Krokstad S, Vaaler AE. Factors associated with a positive occupational outcome during long-term central stimulant treatment in adult ADHD. Atten Defic Hyperact Disord. 2014;6(4):281-290.

83. Volkow ND, Ding YS, Fowler JS, et al. Dopamine transporters decrease with age. J Nucl Med. 1996;37(4):554-559.

84. Herrmann N, Rothenburg LS, Black SE, et al. Methylphenidate for the treatment of apathy in Alzheimer disease: prediction of response using dextroamphetamine challenge. J Clin Psychopharmacol. 2008;28(3):296-301
85. Westover AN, Halm EA. Do prescription stimulants increase the risk of adverse cardiovascular events? a systematic review. BMC Cardiovasc Disord. 2012;12:41.

86. Dalsgaard S, Kvist AP, Leckman JF, Nielsen HS, Simonsen M. Cardiovascular safety of stimulants in children with attention-deficit/ hyperactivity disorder: a nationwide prospective cohort study. $J$ Child Adolesc Psychopharmacol. 2014;24(6):302-310.

87. Olfson M, Marcus SC, Zhang HF, Wan GJ. Continuity in methylphenidate treatment of adults with attention-deficit/hyperactivity disorder. J Manag Care Pharm. 2007;13(7):570-577.

88. Solanto MV, Marks DJ, Wasserstein J, et al. Efficacy of meta-cognitive therapy for adult ADHD. Am J Psychiatry. 2010;167(8):958-968.

89. Weiss M, Murray C, Wasdell M, Greenfield B, Giles L, Hechtman L. A randomized controlled trial of CBT therapy for adults with ADHD with and without medication. BMC Psychiatry. 2012;12:30.

90. Sheehan DV. The Anxiety Disease. New York, NY: Charles Scribner and Sons; 1983

91. Stevenson CS, Stevenson RJ, Whitmont S. A self-directed psychosocial intervention with minimal therapist contact for adults with attention dficit hyperactivity disorder. Clin Psychol Psychother. 2003; 10:93-101.

92. Stevenson CS, Whitmont S, Bornholt L, Livesey D, Stevenson RJ. A cognitive remediation programme for adults with Attention Deficit Hyperactivity Disorder. Aust N Z J Psychiatry. 2002;36(5):610-616.

93. Emilsson B, Gudjonsson G, Sigurdsson JF, et al. Cognitive behaviour therapy in medication-treated adults with ADHD and persistent symptoms: a randomized controlled trial. BMC Psychiatry. 2011;11:116.

94. Safren SA, Sprich S, Mimiaga MJ, et al. Cognitive behavioral therapy vs relaxation with educational support for medication-treated adults with ADHD and persistent symptoms: a randomized controlled trial. JAMA. 2010;304(8):875-880.

95. Virta M, Salakari A, Antila M, et al. Short cognitive behavioral therapy and cognitive training for adults with $\mathrm{ADHD}$ - a randomized controlled pilot. Neuropsychiatr Dis Treat. 2010;6:443-453.

96. DuPaul GJ, Power TJ, Anastopoulos AD, Reid R. ADHD Rating Scale-IV. Checklists, Norms and Clinical Interpretation. New York, NY: The Guilford Press; 1998.

97. Kooij JJ, Francken MH. DIVA 2.0. Diagnostic Interview ADHD in Adults. The Netherlands: Diva Foundation; 2010.

98. Ward MF, Wender PH, Reimherr FW. The Wender Utah Rating Scale: an aid in the retrospective diagnosis of childhood attention deficit hyperactivity disorder. Am J Psychiatry. 1993;150(6):885-890.
Neuropsychiatric Disease and Treatment

\section{Publish your work in this journal}

Neuropsychiatric Disease and Treatment is an international, peerreviewed journal of clinical therapeutics and pharmacology focusing on concise rapid reporting of clinical or pre-clinical studies on a range of neuropsychiatric and neurological disorders. This journa is indexed on PubMed Central, the 'PsycINFO' database and CAS,

\section{Dovepress}

and is the official journal of The International Neuropsychiatric Association (INA). The manuscript management system is completely online and includes a very quick and fair peer-review system, which is all easy to use. Visit http://www.dovepress.com/testimonials.php to read real quotes from published authors. 